\title{
Why Risk Analysis Isn't Working
}

\author{
William K. Hall \\ Graduate School of Business Administration, The University of Michigan
}

\begin{abstract}
In this article the author argues that despite its popularity among researchers and managers alike, Risk Analysis as a management tool has not been successful. He postulates that in the end managers will give up attempting to make formal analysis of risks. substituting more effective means of living with the 'results' of those risks as they arise.
\end{abstract}

I N SPITE OF THE MYRIAD OF TOOLS AND METHODologies developed in the management sciences over the past decade, it is probably safe to say that the methodology of risk analysis for evaluating capital investment decisions has generated the most excitement among researchers and managers alike. While a number of researchers and a few companies were promoting this tool before 1964, the popularity of risk analysis accelerated after David Hertz ${ }^{1}$ wrote his now 'classic' article, where he concluded:

In actual practice, however, the conventional methods (for evaluating capital investments) do not work out satisfactorily. Why? The reason, as we have seen earlier in this article, and as every executive and economist knows, is that the estimates used in making the advance calculations are just that-estimates. More accurate estimates would be helpful, but at best the residual uncertainty can easily make a mockery of corporate hopes. Nevertheless, there is a solution. To collect realistic estimates for the key factors means to find out a great deal about them. Hence, the kind of uncertainty that is involved in each estimate can be evaluated ahead of time. Using this knowledge of uncertainty, executives can maximize the value of the information for decision making.

The value of computer programs in developing clear portrayals of the uncertainty and risk surrounding alternative investments has been proved. Such programs can produce valuable information about the sensitivity of the possible outcomes to the variability of input factors and to the likelihood of achieving various possible rates of return. This information can be extremely important as a backup to management judgment. To have calculations of the odds on all possible outcomes lends some assurance to the decision makers that the available information has been used with maximum efficiency.
Since the Hertz article, risk analysis has been heavily promoted as a tool for improving the evaluation of investments in research and development, new products, new facilities, mergers and acquisitions, and other strategic decisions faced by the modern business firm. During the past decade, almost all graduates of MBA programs have obtained a working knowledge of the tool.* Most large corporations have sent their managers and planners to seminars on the subject. Computer programs to implement the procedure have appeared on almost all commercial time-sharing systems, and many companies have developed these programs for their specialized internal applications. Indeed, some companies have even changed their capital investment procedures to require a risk analysis evaluation as a part of all capital appropriation requests. One writer on the subject has even suggested that risk analysis may ultimately become the 'slide rule of the corporate executive'.

During this same period, academic researchers have developed more sophisticated models and management procedures for implementing risk analysis. Techniques for eliciting the subjective probabilities and utility functions necessary for a comprehensive risk analysis have been proposed and refined, ${ }^{2}$ and financial theorists are currently attempting to link risk analysis with capital structure analysis, leading to a revised theory of business decision-making under uncertainty. ${ }^{3}$

All of this enthusiasm for risk analysis has not gone unchallenged. For example, in a study of the implementation problems encountered with risk analysis in four firms in the oil industry, Carter ${ }^{4}$ has tried to delineate those factors which have

"Indeed, there is some evidence that they have learned their lessons well. When faced with a case-study situation where one of the issues was whether to develop a deterministic or probabilistic long range planning model, 17 out of 28 of this author's students in a recent class opted for the probabilistic model on the grounds that it would be more 'realistic' and provide more 'information' for management. 
helped a hindered successful implementation. He suggests that the degree of success with risk analysis will depend on the resolution of the following questions:

How mature was the risk analysis technique when each company decided to use it?

What were the origins of the decision to adopt it?

How was it fitted in with company organization?

How were the managers who were supposed to use and benetit from the technique prepared for handling it?

How were the data generated, and how were they put together in model form?

What role did top management reserve for itself in deciding to install risk analysis?

Whom did top management assign to shepherd the project along?

In addition, Carter offers some problems inherent in any application of risk analysis:

The company must decide what, exactly, risk analysis can do for it - it must see that the relevance of risk analysis to the decisions its managers must make is carefully spelled out.

For the technique to work, various kinds of assessments of risks and probahilities must be obtained from individual managers. This is not easy to do.

Once the assessments, the data, and the conclusions that can be drawn from them are clear, managers must trade off risk against return in a more or less structured way. Again, this presents a real problem.

Procedures for evaluating and controlling projects must be adjusted for some of the after-effects of risk analysis.

Company problems and solution procedures must be brought into close alignment-otherwise the technique just cannot work.

In another study of the impact of risk analysis on decision-making with the firm, Root $^{5}$ has examined the role of this tool in new product planning. $\mathrm{He}$ comments:

The usual argument for using a risk analysis approach is that a firm attempting to decide whether to make a major financial commitment to a new product must consider and compare many alternatives, and to do this properly there should be an assessment of risk rather than the use of only single-point estimates. Although this philosophy seems incontrovertible, there is no evidence of any great rush to accept this theoretically better method. The reason, of course, is the impossibility of demonstrating in practice that such a technique will lead to better decisions or improved profits.

The intent in this paper is to take yet another look at the real impact of risk analysis on capital investment planning. The basic conclusion is that risk analysis is not having-and will not have-a measurable, positive impact on the planning process in large firms. This conclusion is drawn from empirical observations from two sources:

(1) In depth studies of the decision-making process leading to major new product investments in four 'Fortune 500' manufacturing firms. Two of these firms were attempting to use risk analysis in the evaluation of capital investments, and the other two were studying the technique for possible future implementation.

(2) Interviews with senior managers in 12 large firms operating as either manufacturing, utility, or financial institutions. In all these firms, management was aware of risk analysis, and a limited attempt had been made to apply the tool to an experimental basis in almost half.

There is no way to characterize this sample of firms, projects, and managers as a random sample of current industrial practice. ${ }^{*}$ However, in discussing this study with other managers in other firms, this author has some reason to believe that the observed practices and subsequent impressions and conclusions are representative of the state of the art.

In none of the firms studies was there evidence that the application of risk analysis was improving or could improve the capital investment evaluation process. In fact, in several of the firms which were attempting risk analysis, there was a strong feeling on the part of managers that the company should return to deterministic financial evaluations. (This eventually happened in two of the companies in this sample.)

The conclusion that risk analysis is not working -and probably will not work-will come as a disturbing finding to those researchers and staff analysts who have been promoting the tool. Indeed, some staff analysts in some of the firms in this author's sample and a number of academicians will argue with these findings. Their argument goes roughly as follows:

At the present stage of development, risk analysis may be too sophisticated for senior managers who were not trained in the modern business sciences. However, as new, bettertrained managers come along, and as the complexities and uncertainties of the business environment grow, successful implementation will also grow.

Unfortunately, it is a part of this argument-the complexity and uncertainty of the future business environment-which will work against risk analysis in the long run, not for it! In addition, the internal decision-making mechanisms of the modern business firm operating in this rapidly changing environment make- and will continue to make-risk analysis a tool of very limited applicability in improving the capital investment process. The intent in this paper is to elaborate on this point and to offer some positive guidance for those who are attempting to improve the capital investment process.

\section{THE UNCERTAINTY OF UNCERTAINTY}

Theoretically, the idea of quantifying uncertain elements in decision-making is hard to disputeboth on the grounds that this procedure brings more information into the analysis and on the grounds that the procedure makes assumptions and

*In all cases the companies studied have insisted that their identities and specific corporate practices not be divulged. However, all were leaders in their industry and are considered to be progressive and well-managed. 
differences of opinion explicit. In practice, however, the idea fails on at least two grounds:

(1) The decision as to who should quantify uncertainty and how this should be done.

(2) The decision as to what uncertainties should be quantified.

We shall return to the first question later, elaborating on the second issue at this time.

As the rate of change and complexity of the business environment grows, the uncertainty of uncertain events must also grow. Toffler ${ }^{6}$ makes this point clearly in his recent best-selling book:

In the face of such an upheaval (in the purposes of economic activity), even the most sophisticated tools of today's economists are helpless. Input-output tables, econometric models - the whole paraphernalia of analysis that economists employ simply do not come to grips with the external forces-political, social, and ethical-that will transform economic life in the decades before us.

In addition, a large number of specific examples are available to support this premise with respect to the capital investment process. For example:

(1) A large, integrated mining company conducted a relatively sophisticated risk analysis in attempting to evaluate a new processing venture. Ranges for future costs, volumes, and revenues were carefully elicited and the liklihoods of various values within these ranges were quantified. However, the asset life was assumed to be deterministic (20 years in this case) and 4 years after the project was approved, the processing venture was seized by a foreign government.

(2) In analyzing future foreign investments in the late $1960 \mathrm{~s}$, at least one major oil company interviewed by this author (and probably many others) neglected to consider and quantify what has turned out to be the dominant risk in industry investment planning - the Middle East political situation.

(3) As far as this author has been able to determine, the risks of the explosive inflation in the United States in 1973 were not adequately quantified in any sector-including the Government. Indeed, one senior economic advisor has admitted, 'This inflation is very disconcerting ... it took us by surprise.'

(4) As recently as the early summer of 1973, senior automobile executives were not even considering a major domestic energy problem in their investment planning-let alone quantifying this risk. Nevertheless, everyone in the industry today will admit that this is now the biggest risk faced by the industry and that different investment decisions would have been made had this risk been properly assessed at any earlier date.

(5) During the early 1970 s, the risks of raw material supply shortages were not considered in capital investment planning by any of the firms in this sample. However, today these risks (along with the energy problem) dominate future profitability calculations for almost all investment decisions.

It is easy, of course, to disregard these experiences as examples of poor planning. Yet managers and analysts in each of these situations claim unanimously that 'we had no warning ... the world has changed and is changing in a way it has never changed before'.

The point here is that the future will be different from the past and that past and present experiences will become increasingly less relevant in predicting the future. More important, those events which are not and cannot be predicted will have an increasingly larger impact on the future outcomes of current decisions. Indeed, it is likely that the world of the future will have more and more managers trapped by this proverbial law: 'If its not planned for, it will happen.'

If we accept the promise of the uncertainty of future uncertainty, then risk analysis is very likely to result in a 'type three error'-an elaborate attempt to resolve the wrong problem. It is certainly becoming more and more difficult to argue that limited managerial resources should be allocated to the careful and precise quantification of unccrtainty, when the rcal risk is that the wrong risks will be quantified. And there is growing evidence that senior managers who reject the sophistication of risk analysis have in fact accepted the promise of future uncertainty. Consider, for instance, the following comments recently made by a senior vice president in the automotive industry.

\footnotetext{
"In planning for strategic investments today, the only real important questions are the ones you can't answer. . . . As much as we want to talk about this planning process with poly syllabic words and the like, in the end you still made the decision by taking a hell of a gamble."
}

\section{THE MYTH OF THE DECISION-MAKER}

Unfortunately, even if our mythical crystal ball were suddenly to improve to the point where we could predict future uncertainties-let alone the future-risk analysis still won't work. This is because the tool conflicts with the internal decisionmaking mechanisms in today's large organization. Consider, for example, the question as to whose subjective probabilities and utility functions should be elicited in a risk analysis. The typical answer is the 'decision-maker's', for example, as Brown ${ }^{7}$ puts it, "personalistic decisions analysis consists of modeling what an executive has in his head and thereby seeks to impose some logical consistency to his decision making'.

The problem is that investment decisions in large organizations are not made by an executive or even a committee of executives. Instead the process is governed by the sequential interactions of many parties in the organizational hierarchy. While top 
management may make the final 'go-no go' decision, the inputs to this binary process have been massaged and shaped to the point where the ultimate decision is almost always routine and in many cases even automatic. In addition, a number of researchers $^{8}$ have noted that the inputs to this process arise sequentially from all levels of the organization. Indeed, one can find a great deal of support for the argument that investment policy is shaped through the alternatives lower level managers choose to 'serve up' to senior management-even in those organizations where planning is supposed to be centralized at the senior executive level.

\section{THE PROCESS OF INVESTMENT PLANNING}

This 'diffuse' process of investment planning in the modern firm, molded by the bottom up support of a limited set of alternatives, has some significant effects on risk-taking. First of all, as Bower ${ }^{9}$ has observed; 'a plan is something a network of managers wants to do because it is in their interest to do so'. As a result, the numbers used to support a project will reflect commitment to the project, and these will change as this commitment varies. In at least two situations studied by this author, inputs into a risk analysis model were consciously changed by project analysts, thereby changing the model outputs in an effort to sway commitments at other organizational levels. (It is important to understand that the numbers used to justify an investment project were not changed over time to sabotage the project or the technique of analysis; they were changed to get the project approved. These changes might be upward or downward, and in all cases they could be justified as 'reasonable estimates'.) Since this is the way numbers evolve in the 'real world', it seems senseless to develop more sophisticated and more expensive ways of eliciting and massaging these numbers.

The process of decision making in the real world affects risk taking behavior in other ways. In fact, it can be argued that the firms studied in this project did not take risks-instead they devised procedures for dividing, delaying, and sharing the risks inherent in the new products being considered. Risks were divided in the sense that financial sponsorship was requested only for the narrowlydefined tasks to be undertaken between formal project reviews. While formal and informal long range plans existed (at least on paper), these were de-emphasized in favor of short range, tactical plans in requesting funding. The problem, of course, is that these sequences of short-range fundings eventually led to the point where major commitments must be made. In some of the firms studied, integrating management was aware that these decision points were coming, but they were unprepared to act when they arrived. The result was 'risk delaying', where major decisions were held in limbo while political, economic and technological uncertainties resolved themselves. This 'holding' period was frequently of long duration-more than 10 years for a major product investment in one of the firms examined. It always ended when the overall level of commitment to the project changed-either through a change in management or a change in the business environment. As one senior manager in a large manufacturing firm put it, 'Usually the way that decisions get made in our firm is that we wait so long the decision gets made for us ... it becomes a simple matter of survival.' It is interesting to note that these subsequent changes in commitment to the investment project under consideration were unforeseen at the inception of the projectamplifying again some of the uncertainties of uncertainty.

Superimposed on this entire process was 'risk sharing' among members of the organization. The diffuseness of decision making in the formal product planning and review process was such that no one person could take all the blame if things went bad, but everyone could claim most of the credit when things went right - supporting again the myth of the well-identified decision-maker in the modern business firm.

\section{SOME IMPLICATIONS}

There is little argument that analysis should be a part of the investment process-if for no other reason than, as Easton ${ }^{10}$ puts it:

(1) Businessmen want to be normative.

(2) Important decision must be defensible.

(3) The numbers form a common language for communication.

Still, in the face of uncertain uncertainties and a diffuse, commitment-oriented process of investment planning in large firms, this author has become convinced that risk analysis results in oversophisticated 'over-kill'.

In the end the numbers associated with a project are likely to reflect the outcome of the planning process-not the inputs to the process. In addition, future uncertainties almost always guarantee that these numbers will be proven wrong. Consequently, it would appear that simple, straightforward deterministic analysis of capital investments is sufficient to provide the numbers necessary to balance individual commitments against corporate well-being in an unstable and rapidly changing environment. In fact, there may even be an inherent danger in applying risk analysis in such an environment. Quantification-cven unbiased quantification-of the wrong risks is apt to lead to 'tunnel vision'-diverting management attention from an open consideration of fundamental risks and other options. If this occurs the application of risk analysis narrows the information base instead of broadening it.

More important, however, is the fact that the particular methodology of analysis is less significant 
than the overall process of intra-firm decisionmaking and the process of implementing subsequent plans in terms of its impact on the future of the firm. It would appear that the socio-political aspects of the investment planning process in large firms offer a greater challenge for management researchers than the search for new tools to impose on this process. It is surprising how little is known about the effects of modifying this planning process within large organizations by changing organizational systems, reward systems, and other aspects of the control process. The study of the actual process of strategy formulation-as opposed to normative explanations as to how strategy should be formulated in an ideal world-is in its infancy.

Still, the uncertainty of uncertainty will prevail, regardless of how corporate strategy evolves, and regardless of what analytical tools are employed. The implication of this fact is that flexibility in strategy implementation will become increasingly important to the large firm. Here again, there is some evidence that managers are beginning to recognize this-witness the number of firms which are adding capacity in small rather than large lumps - even when economics of scale would dictate the opposite conclusion in a deterministic (but unrealistic) world. This author predicts that this tendency to 'keep options open' in planning should and will grow during the next decade.

In the end, it is likely that managers will give up the formal analysis of risks, substituting instead better means of living with risks as they arise. The oft-maligned philosophy of 'taking them as they come' will rise again. Indeed, a 'radical' observer of the current managerial process might even conclude that 'skill and judgment' may rise again to take their places ahead of 'tools and analysis'. It certainly would appear that the risks in using analysis are drastically increased by these qualitative factors, and that these latter factors must become the focus of future efforts for both managers and researchers.

\section{REFERENCES}

(1) D. B. Hertz, Risk Analysis in Capital Investment, Harvard Business Review, pp. 95-106 (1964).

(2) See, for instance, Howard Raiffa, Decision Analysis, Addison-Wesley (1968) or R. Brown \& C. Peterson, Decision Analysis for the Executive, Holt, Rinehart $\&$ Winston (1973).

(3) See, for instance, Haley \& Schall, The Theory of Financial Decisions, McGraw-Hill (1973).

(4) E. S. Carter, What are the risks of risk analysis, Harvard Business Review, pp. 72-82 (1972).

(5) H. P. Root, Implementation of risk analysis models for the management of product innovations, Proceedings on International Symposium on Computer Simulation, University of Gothenburg (1973).

(6) A. Toffler, Future Shock, Random-House (1973).

(7) R. V. Brown, Do managers find decision theory useful ?, Harvard Business Review, May-June, p. 78 (1970).

(8) See, for example, W. K. Hall, Strategic planning, product innovation, and the theory of the firm, Journal of Business Policy, 3 (3), 19-27, Spring (1973).

(9) J. L. Bower, Managing the Resource Allocation Process, Harvard (1970).

(10) Allen Easton, Complex Management Decisions Involving Multiple Objectives, Wiley (1973). 